\title{
Evolution of hypothyroidism in familial goitre due to deiodinase deficiency: report of a family and review of the
} literature

\author{
Harry J. Hirsch, Shmuel Shilo and Irving M. Spitz
}

Department of Endocrinology and Metabolism, Shaare Zedek Hospital and Hadassah Hebrew University Medical School, Jerusalem, Israel and The Center for Biomedical Research, The Population Council, New York, N.Y., USA

\begin{abstract}
Summary: We studied two sisters who developed large non-toxic goitres in adolescence. Deiodinase deficiency was diagnosed by a rapid thyroid uptake of radioactive iodine (RAI) at 2 hours associated with a marked fall in thyroidal ${ }^{131}$ I by 24 hours. Serial RAI scans in the second patient documented evolution of the iodine-deficient state. Conservation of intra-thyroidal iodine stores was maintained by avid iodine uptake and failure to release organified ${ }^{131}$ I. With progressive loss of inorganic iodine, hypothyroidism developed, associated with a rise in serum TSH which further exacerbated the loss of iodine. Treatment with $\mathrm{L}$-thyroxine resulted in an improvement of thyroid function, but normalization was achieved only after small doses of Lugol's iodine were administered.

These studies illustrate the variable nature and late onset of an inborn error of thyroid metabolism. This family supports an autosomal recessive mode of inheritance for deiodinase deficiency. We have documented progression from a euthyroid to hypothyroid state resulting from decompensation of iodine conservation mechanisms.
\end{abstract}

\section{Introduction}

We have studied two sisters who developed large nontoxic goitres in adolescence. A defect in iodine conservation due to deiodinase deficiency was diagnosed on clinical grounds and because of the distinctive radioactive iodine uptake profiles. Serial studies of thyroid function and radioactive iodine (RAI) uptake documented transition from a euthyroid to hypothyroid state in each sister. The change in thyroid function secondary to the enzyme defect was most likely a result of continuing iodine loss.

\section{Methods}

Serum thyroid stimulating hormone (TSH) was determined by a previously described radioimmunoassay using antisera kindly supplied by the National Pituitary Agency, National Institute of Arthritis, Metabolism and Digestive Diseases (NIAMDD) (Spitz et al., 1981). The TSH standard (68/38) was kindly provided by the Division of Biological Standards and Control, Holly Hill, Hampstead, London.

Correspondence: H.J. Hirsch, M.D., Dept. of Pediatrics, Shaare Zedek Medical Center, P.O. Box 293, Jerusalem, Israel

Accepted: 6 December 1985
The mean \pm s.d. basal TSH levels in 14 female controls aged 18-26 years was $3.7 \pm 1.3 \mathrm{mU} / 1$ and the range was from $1.8-6.0 \mathrm{mU} / \mathrm{l}$. Following $200 \mu \mathrm{g}$ thyrotrophin releasing hormone (TRH) i.v., the peak TSH response was $22.8 \pm 8.5 \mathrm{mU} / 1$ and the range was from $12-38.7 \mathrm{mU} / 1$.

Total thyroxine (T4), total tri-iodothyronine (T3), and $T 3$ resin uptake (T3RU) were measured using test kits supplied by Ames Co., Division of Miles Laboratories, Inc. The range of normal values for T4 are 48 to $157 \mathrm{nmol} / 1$, for T3 from 1.15 to $3.38 \mathrm{nmol} / 1$, and for T3RU from $0.42-0.54$, respectively. All samples from our two patients were analysed in a single assay run, thereby eliminating any inter-assay variation. The initial T4 determination for patient 2 was performed in a competitive protein binding assay in which the normal range was 32 to $103 \mathrm{nmol} / \mathrm{l}$. The normal ranges for ${ }^{131}$ I thyroid uptake are 5 to $12 \%$ at 2 hours and 15 to $40 \%$ at 24 hours.

\section{Case reports}

Case 1

This 23 year old woman was born in Jerusalem to nonconsanguineous Tunisian Jewish parents. Except

(C) The Fellowship of Postgraduate Medicine, 1986 
for her younger sister (Case 2), no other family members have thyroid disease. She was afflicted with poliomyelitis, at age 18 months, resulting in paralysis of her left leg. Following a cerebral concussion, she developed a focal seizure disorder and from 1969 she was treated with primidone and diphenylhydantoin.

In 1971 (aged 17 years) she underwent a craniotomy because of focal seizures. A goitre was noted and on questioning she admitted to weight loss and constipation, but denied other symptoms of thyroid dysfunction. By November 1974, the thyromegaly had increased in size, serum T4 was $126 \mathrm{nmol} / 1$ and T3RU was 0.55 . Results of an ${ }^{131} I$ thyroid uptake were $74 \%$ at 2 hours and $18 \%$ at 24 hours. In 1975 a repeat ${ }^{131}$ I uptake showed $76 \%$ at 2 hours, $70 \%$ at 4 hours, $56 \%$ at 6 hours, and $17 \%$ at 24 hours.

She was first seen in our clinic in 1977 at which time she denied all symptoms of hypothyroidism except for constipation. Her pulse rate was $60 /$ minute and blood pressure $110 / 60 \mathrm{mmHg}$. She was of average intelligence and her hearing was normal. The thyroid gland was diffusely enlarged, soft, and had a prominent bruit. Serum T4 was less than $24 \mathrm{nmol} / 1$, T3RU was 0.23 . Total $\mathrm{T} 3$ was $0.61 \mathrm{nmol} / \mathrm{l}$, and TSH was greater than $200 \mathrm{mU} / 1$. Treatment with L-thyroxine, $200 \mu \mathrm{g} /$ day for 8 weeks, raised serum T4, T3 and T3RU values and decreased TSH levels. T3 and T3RU values were normalized on the $200 \mu \mathrm{g}$ dose of L-thyroxine, but an L-thyroxine dosage of $300 \mu \mathrm{g} /$ day was needed to achieve normal serum levels of T4. Even at this higher dosage, TSH levels remained elevated during the 4month treatment period. Lugol's solution, one drop daily, resulted in normal levels of serum T4 and TSH. Values remained within the normal range when the iodine dose was reduced to one drop of Lugol's solution every other day. On this regimen, she is well and works as a telephone switchboard operator.

Her marked thyromegaly gradually disappeared as did the bruit. After 8 months of treatment she was left with a small residual multinodular goitre.

\section{Case 2}

The sister of Case 1 was well until age 12.5 years when she first noticed a goitre. L-thyroxine treatment was begun but the patient discontinued the medication after 2 weeks. She first presented to our clinic at age 16 years because of gradually increasing size of the goitre. She complained of nervousness, easy fatiguability, and occasional dysphagia. Menarche was at age 14 and periods were irregular, but occurred at least once every 2 months. She attended 11 th grade, was an average student, and had no hearing defect. Her weight was $56.8 \mathrm{~kg}$ (50th percentile), height $158.8 \mathrm{~cm}$ (25th percentile), pulse rate 76/minute, and blood pressure 110 / $76 \mathrm{mmHg}$. Her thyroid gland was diffusely enlarged, soft, non-tender and without palpable nodules and measured $5.4 \mathrm{~cm}$ (right lobe), $5 \mathrm{~cm}$ (left lobe), and $3 \mathrm{~cm}$ (isthmus). Breast development was Tanner Stage V. There was no galactorrhea. Axillary and pubic hair were Tanner Stage IV. There were no signs of hypo- or hyperthyroidism. Serum T4 was $38 \mathrm{nmol} / 1$, T3RU 0.47 , total T3 $2.84 \mathrm{nmol} / 1$, and TSH $2.5 \mathrm{mU} / 1$. Serum TSH rose to a peak level of $21.4 \mathrm{mU} / 120$ minutes after an i.v. bolus of TRH. This is in the normal female range. A technetium-99 scan showed a diffusely enlarged gland. The RAI uptake was markedly increased at 2 hours and remained high at 24 hours with almost no decrease by 96 hours. Potassium perchlorate, $400 \mathrm{mg}$ p.o., failed to discharge additional ${ }^{131}$ I from the gland. In February 1981, L-thyroxine $200 \mu \mathrm{g} /$ day was begun in an attempt to reduce the size of the gland.

When next seen in June 1981, the goitre was increased in size and both a bruit and thrill were noted. She admitted to having discontinued the medication at least 2 months previously. Serum T4 was $14 \mathrm{nmol} / \mathrm{l}$, T3RU 0.24 , total $T 30.38 \mathrm{nmol} / 1$, and TSH was greater than $100 \mathrm{mU} / 1$. Thyroid microsomal and thyroglobulin antibodies were negative.

Thyroid uptake of ${ }^{131} \mathrm{I}$ was rapid at 2 hours, but decreased rapidly to $9.7 \%$ at 24 hours. L-thyroxine $200 \mu \mathrm{g} /$ day was reinstituted, but compliance was poor. In January 1983, Lugol's solution was substituted for L-thyroxine treatment. Because of poor patient compliance, it has not been possible to assess the effect of this treatment.

\section{Discussion}

The development of goitrous primary hypothyroidism in two sisters out of eight siblings in this Tunisian Jewish family is consistent with an autosomal recessive mode of inheritance. Although Kusakabe proposed autosomal dominant inheritance (Kusakabe \& Miyake, 1963), other reported cases of familial goitre due to deiodinase deficiency follow an autosomal recessive pattern (Stanbury et al., 1956; Ismail-Beigi \& Rahimifar, 1977; Codoccioni et al., 1978). Primary hypothyroidism was documented by low serum T4 and T3 levels and markedly elevated levels of TSH.

Thyroid hormone biosynthesis is a complex process involving a series of specific enzymatic mechanisms. These include trapping of iodide within the thyroid, oxidation by a peroxidase enzyme, formation of mono- and diiodotyrosine (MIT and DIT), then coupling to form T4 and T3, storage of the T4 and T3 within the colloid as peptide linked residue bound to thyroglobulin, and proteolysis and release of T4 and T3 into the circulation (Stanbury et al., 1978). Proteolysis also releases some MIT and DIT, present in the thyroglobulin, but these are deiodinated by potent microsomal enzymes located in thyroid paren- 
chymal cells which prevent the release of these precursors into the blood stream. Most of the free iodide is conserved for reutilization by parenchymal cells (Stanbury et al., 1978).

The ${ }^{131}$ I uptake results are consistent with a thyroid enzyme defect. Thyrotoxicosis and iodine deficiency are the most common causes for a rapid 2 hour RAI uptake, but the low T4, T3 and T3RU and elevated TSH levels exclude the diagnosis of hyperthyroidism.

Both sisters were born and raised in Jerusalem and therefore, were not iodine-deficient due to inadequate iodine content of their diets. Similarly, dietary history did not reveal any source of goitrogen ingestion.

Increased RAI uptake is observed in peroxidase defect, Pendred syndrome, deiodinase deficiency, and thyroglobulin or coupling defect (Stanbury et al., 1978). The lack of ${ }^{131}$ I discharge following perchlorate administration and positive response to small doses of iodine in Case 1, as well as the normal auditory ability in both sisters argue against peroxidase deficiency and Pendred's syndrome. Similarly, an effective response to small doses of Lugol's solution would not be predicted in the thyroglobulin defect or coupling disorders.

The clinical and laboratory findings in our two patients are diagnostic of a deiodinase enzyme deficiency. This defect was originally described in a highly consanguineous family of itinerant Scottish tinkers with goitrous hypothyroidism associated with elevated RAI uptakes (Hutchison \& McGirr, 1954). In most of these patients whose ages ranged from 2-20 years, the thyroidal ${ }^{131}$ I content was markedly elevated at 2 hours, but decreased significantly by 24 hours. In two of their patients however, the thyroidal ${ }^{131}$ I uptake remained high ( $75 \%$ and $77 \%$ ) at 24 hours, which is similar to what we observed in Case 2 in 1980.

Stanbury et al. (1956) showed that when ${ }^{131}$ I-MIT and ${ }^{131}$ I-DIT were administered to patients with familial goitres due to deiodinase deficiency, the labelled precursors were excreted unchanged in the urine, demonstrating that deiodination did not occur in these subjects. The enzyme responsible for deiodinating iodotyrosines is present not only in thyroid tissue, but also in liver and kidney (Kusakabe \& Miyake, 1964). McGirr et al. (1959) detected mild defects in thyroidal deiodination capacity in four apparently healthy members of the original tinker pedigree. This observation was confirmed by Codoccioni et al. (1978) who found intermediate values of deiodinating activity in heterozygote carriers.

The defect in deiodination of thyroid hormone precursors prevents the normal iodine 'recycling' mechanism, and leads to a state of iodine deficiency. The euthyroid state may be maintained by an increased rate of thyroidal iodine uptake resulting in adequate recirculation of iodine to allow the hyperplastic thyroid to maintain normal serum levels of $L$ thyroxine (Kusakabe \& Miyake, 1963). This mechanism may explain the late onset of goitre in this congenital enzyme defect. The transition from a euthyroid to hypothyroid state observed in our two patients suggests that their compensatory mechanisms were overwhelmed by the continuing and increasingly severe state of iodine deficiency. Similarly, the changing pattern of RAI uptake in Case 2 reflects the various degrees of iodine deficiency. In March 1980, serum hormone levels and the TSH response to TRH were normal. Administered RAI was avidly trapped and organified by the iodine-deficient thyroid gland. The lack of release of organified ${ }^{131} I$ indicated a need for the gland to conserve its depleted iodine stores to maintain the euthyroid state. With continuing iodine loss the RAI uptake pattern changed to that observed in June 1981. Release of thyroidal ${ }^{131} I$, after an early rapid uptake, corresponds to stimulation of thyroid hormone synthesis and release due to the elevated TSH levels in the decompensated hypothyroid state.

Administration of small doses of iodine compensated for the loss of iodine and corrected all parameters of thyroid function. Alternatively, Lthyroxine may be used to treat this condition (Stanbury et al., 1978). The failure of a $200 \mu \mathrm{g} /$ day dose of Lthyroxine to normalize thyroid function in Case 1 may have been due to poor compliance or decreased bioavailability of the L-thyroxine preparation. Our studies of these two sisters emphasize the variable manifestations of a genetic defect in thyroid metabolism. Despite the congenital nature of the enzyme deficiency, full expression of the defect did not appear until late adolescence. Progression to hypothyroidism represents decompensation of the iodine conservation mechanism.

\section{References}

CODOCCIONI, J.L., RINALDI, J.P. \& BISMUTH, J. (1978). The test of overloading of 1-diiodotyrosine (DIT) in the screening of iodotyrosine dehalogenase deficiency. Acta Endocrinologica, 87, 95 .

HUTCHISON, J.H. \& MCGIRR, E.M. (1954). Hypothyroidism as an inborn error of metabolism. Journal of Clinical Endocrinology and Metabolism, 14, 869.

ISMAIL-BEIGI, F. \& RAHIMIFAR, M. (1977). A variant of iodotyrosine-dehalogenase deficiency. Journal of Clinical Endocrinology and Metabolism, 44, 499.

KUSAKABE, T. \& MIYAKE, T. (1963). Defective deiodination of $I^{131}$ labeled L-diiodotyrosine in patients with simple goiter. Journal of Clinical Endocrinology and Metabolism, 23, 132.

KUSAKABE, T. \& MIYAKE, T. (1964). Thyroidal deiodination defect in three sisters with simple goiter. Journal of Clinical 
Endocrinology and Metabolism, 24, 456.

MCGIRR, E.M., HUTCHINSON, J.H. \& CLEMENT, W.E. (1959). Sporadic goitrous cretinism: dehalogenase deficiency in the thyroid gland of a goitrous cretin and in heterozygous carriers. Lancet, ii, 823.

SPITZ, I.M., LEROITH, D., HIRSCH, H., CARAYON, P., PEKONEN, F., LIEL, Y., SOBEL, R., CHORER, Z. \& WEINTRAUB, B. (1981). Increased high-molecular-weight thyrotropin with impaired biologic activity in a euthyroid man. New England Journal of Medicine, 304, 278.

STANBURY, J.B., KASSENAAR, A.A.H., MEIJER, J.W.A. \& TERPSTRA, J. (1955). The occurrence of mono- and diiodotyrosine in the blood of a patient with congenital goiter. Journal of Clinical Endocrinology and Metabolism. $15,1216$.

STANBURY, J.B., MEYER, J.W.A. \& KASSENAUR, A.A.H. (1956). The metabolism of iodotyrosines. II. The metabolism of mono- and di-iodotyrosine in certain patients with familial goiter. Journal of Clinical Endocrinology and Metabolism, 16, 848.

STANBURY, J.B., WYNGAARDEN, J.B. \& FREDRICKSON, D.S. (1978). In Metabolic Basis of Inherited Disease, 4th edition. pp. 224-226. McGraw-Hill: New York. 